\title{
A UNIVERSIDADE ABERTA PARA A TERCEIRA IDADE E A EDUCAÇÃO DO IDOSO NAS DISSERTAÇÕES E TESES de 2000 a 2011
}

\author{
Rita de Cássia da Silva Oliveira ${ }^{1}$ \\ UEPG
}

\section{RESUMO}

O presente artigo objetiva analisar as teses e dissertações defendidas no recorte temporal de 2000 a 2011, que possuem como tema de investigação a educação para a terceira idade e a universidade aberta para a terceira idade. Os trabalhos selecionados foram defendidos em Cursos reconhecidos e recomendados pela Capes, elaborando o estado do conhecimento dessa temática. O referencial teórico baseia-se em uma revisão sistemática e nas ideias dos autores que investigam o tema. Realizou-se uma pesquisa bibliográfica e, para coleta de dados, utilizaram-se os meios on line: Domínio Público, Portal da Capes, Programa de Pós-Graduação em Educação e bibliotecas de teses e dissertações das Instituições de Ensino Superior. Constata-se um crescimento expressivo nas investigações, apresentam contribuições relevantes mas também muitas lacunas acerca das categorias selecionadas para a análise.

Palavras-chave: Educação para o idoso; Universidade Aberta para a Terceira Idade; Estado do Conhecimento; Políticas Públicas.

\section{THE OPEN UNIVERSITY FOR THE ELDERLY AND EDUCATION IN THE ELDERLY AND THESIS THESES 2000-2011}

\begin{abstract}
This article aims to analyze the theses and dissertations defended in the time frame from 2000 to 2011, having as a subject of research education for seniors and college open to seniors. Selected works were defended Courses recognized and recommended by Capes, elaborating the state of knowledge of this subject. The theoretical framework is based on a systematic review and ideas of authors who researched. We conducted a literature search and data collection, we used the online media: Public Domain Portal CAPES, the PostGraduate Education and library of theses and dissertations of Higher Education Institutions. There has been a significant increase in investigations present relevant contributions but also many gaps of the categories selected for analysis.
\end{abstract}

Keywords : Education for the elderly . Open University of the Third Age . State of Knowledge. Public Policy

\section{Introdução}

O envelhecimento demográfico é atualmente uma realidade mundial e o Brasil em especial, além de apresentar um grande contingente de idosos, também registra um crescimento acelerado desta faixa etária. Diante desta realidade, as demandas se avolumam e requerem políticas públicas para esta faixa etária que contemplem as necessidades básicas e principalmente que implementem as leis já existentes, muitas restritas ao papel sem efetivação na prática, entre as quais pode-se citar a educação para o idoso e as universidades abertas para a terceira idade. 
Desta maneira, torna-se relevante as pesquisas sobre a velhice e sobre o idoso, enfatizando aqui as investigações sobre as universidades abertas para a terceira idade e sobre a educação do idoso, na busca de superar os estereótipos negativos e os estigmas cristalizados culturalmente sobre esta faixa etária entre os quais se pode citar a incapacidade de aprendizagem dos idosos, que constitui um mito construído no imaginário social brasileiro. Com esta realidade, o idoso apresenta-se vulnerável em relação ao respeito de seus direitos elementares básicos, prescritos na Constituição, entre os quais, a educação.

Embora o idoso, nos últimos anos, tenha conquistado maior visibilidade na sociedade brasileira, devido ao crescimento de pesquisas sobre esta faixa etária, variedade de eventos científicos de relevância, programas e notícias evidenciados pela mídia na qual enaltecem a importância de um envelhecimento ativo e saudável, de certa maneira, diminui os preconceitos que revestem a velhice e, essa faixa etária vem sendo entendida como um campo profícuo para as pesquisas.

Embora por muito tempo, em nossa sociedade capitalista foi desconsiderada e até negada a educação para o idoso, mesmo sendo um preceito constitucional: a educação como direito de todos, hoje abre-se espaço nas diferentes iniciativas das universidades, as quais acolhem os idosos em Programas, projetos e cursos específicos de educação para esta faixa etária.

A educação para o idoso está prescrita na Política Nacional do Idoso (Lei 8842/1994) e no Estatuto do Idoso (Lei 10741/2003). Estas Leis explicitam a importância do poder público incentivando e apoiando a implantação de programas de educação permanente para idosos e a de universidades abertas para a terceira idade.

No ordenamento jurídico não existe uma política educacional para o idoso, mas inclui-se o idoso nas políticas educacionais para os jovens e adultos. Entretanto, com o fenômeno de jovenização da EJA, o idoso fica deslocado pela grande faixa etária que a EJA contempla e, mais uma vez, sente-se desfavorecido nesta modalidade de educação.

Com esta lacuna na educação para o idoso, as universidades abriram espaço criando um campo específico para a educação desta faixa etária, sob a denominação de Universidades Abertas, as quais têm como objetivos a integração, a valorização, elevação da auto estima, aquisição de conhecimentos e atualização, conhecimento dos direitos e dos deveres e ao exercício pleno da cidadania do idoso.

Este artigo é resultado de uma pesquisa que objetivou uma busca e análise sistemática de trabalhos que refletem sobre a educação para o idoso e as universidades abertas para a terceira idade. Realizou-se uma pesquisa bibliográfica, de revisão sistemática de um levantamento das dissertações e teses, sendo o recorte temporal estabelecido entre 2000 a 2011, nos Cursos reconhecidos e recomendados pela Capes, realizando o estado de conhecimento da temática. Foram analisadas 8 dissertações que apresentaram como tema central a universidade aberta para a terceira idade e, 17 dissertações e 2 teses que têm como objeto de estudo a educação do idoso, sendo estas duas as categorias selecionadas neste estudo.

Para a construção dos dados utilizaram-se os meios online: Domínio Público, Portal da CAPES, Programas de Pós-Graduação em Educação e bibliotecas de teses e dissertações das Instituições de Ensino Superior.

Este estudo teve também como objetivo identificar as principais contribuições e lacunas desses trabalhos acerca da universidade aberta para a terceira idade, da educação para o idoso, e elencar os principais autores que fundamentaram teoricamente estes trabalhos. 
Com esta investigação pretende-se divulgar as pesquisas realizadas sobre as temáticas destacadas, na busca de superar os estereótipos negativos e as resistências ainda existentes na sociedade brasileira, superando-as em nome da efetivação do direito do idoso à educação.

\section{Políticas públicas e a realidade do idoso no Brasil}

O fenômeno do envelhecimento está presente praticamente em todas as sociedades contemporâneas e o crescimento do contingente de idosos é real, surgindo como resposta aos avanços da medicina, da tecnologia, da diminuição das taxas de natalidade e de mortalidade no Brasil.

Assim, pode-se afirmar que um dos grandes desafios do século que se iniciou a pouco mais de uma década é equacionar satisfatoriamente as demandas diante deste novo panorama demográfico mundial, com um perfil distinto da população, mais envelhecida, registrando a necessidade da garantia de direitos e de qualidade de vida, com um envelhecimento ativo, saudável e digno.

A dimensão política e social do fenômeno do envelhecimento não pode ser minimizada sob o risco de diminuir este fenômeno, em última instância reduzi-lo apenas à dimensão individual e, com uma diversidade de nuances que despolitiza a seriedade e a influência significativa que a sociedade recebe, garantindo pelo Estado uma posição hegemônica e confortável enquanto fortalece culturalmente estereótipos negativos e cruéis para a velhice.

O paradigma do Brasil jovem hoje está superado pelo registro de 21 milhões de idosos, o que representa cerca de $11 \%$ da população. Este panorama populacional reclama um conhecimento sobre o processo de envelhecimento e da velhice (IBGE, 2010).

Entender do processo de envelhecimento supõe o entendimento de mudanças gradativas no organismo, nos aspectos físicos, psicológicos, nas relações sociais e, pelas quais todos os indivíduos irão passar, mas que não significam incapacidade, apenas mudanças que acontecem com o envelhecimento.

Os preconceitos culturalmente construídos e fortalecidos na sociedade acerca da velhice, por muitas vezes são cruéis e rotulam negativamente os idosos, acarretando situações de vulnerabilidade, fragilidade e marginalização, à medida que são considerados incapazes e improdutivos. Diante desta representação negativa, o idoso é menosprezado e sua experiência e sabedoria acumuladas ao longo dos anos é desconsiderada, retirando o direito de sonhar, de aprender e de viver! (OLIVEIRA, 1999).

Para assegurar que essas discriminações, situações constrangedoras e discriminatórias que vitimizam os idosos sejam superadas devem ser implementadas as políticas públicas.

Segundo Boneti (1997, p.1888), "política pública é o resultado da dinâmica do jogo de forças que se estabelece no âmbito das relações de poder, relações essas constituídas pelos grupos da sociedade civil”.

As demandas sociais são variadas diante do grande número de idosos na sociedade brasileira e situam-se nas diferentes esferas: previdência social, moradia, saúde, cultura, trabalho, educação e segurança.

Como afirma Oliveira et al.(2011), as políticas públicas materializam as ações governamentais e vêm satisfazer as necessidades básicas da população idosa, assegurando o Estado Democrático de Direito do idoso. 
A educação surge como estratégia para empoderar e emancipar o idoso rompendo gradativamente com a marginalização e acena para a construção de uma nova visão de velhice.

Entretanto, não existe política educacional para o idoso no ordenamento jurídico brasileiro, e a legislação educacional contempla a educação básica (educação infantil, ensino fundamental, e médio) e o Ensino Superior, juntamente com outras modalidades de ensino, mas o idoso fica deslocado porque a metodologia, os recursos utilizados não são adequados, somando ainda a falta de professores preparados para atuarem com esta faixa etária.

Em duas leis específicas para o idoso - Lei 8842/1994 Política Nacional do Idoso e a Lei 10.741/2003, Estatuto do Idoso, prescrevem o direito à educação, respeitando as especificidades da idade. Acrescenta-se também a necessidade do poder público estimular a criação de oportunidades de acesso do idoso à educação e também o apoio na criação das universidades abertas para a terceira idade, as quais constituem um espaço peculiar e adequado para a educação do idoso.

Entretanto, o poder público precisa dar mais atenção às questões relativas à educação para o idoso, mesmo na modalidade da EJA, condições específicas que contemplem as necessidades e características desta faixa etária.

\section{A investigação: aspectos metodológicos}

As pesquisas realizadas em mestrados e doutorados, na maioria registram evidências importantes sobre as temáticas abordadas e contribuem significativamente para os avanços científicos na área, em particular neste estudo, colaboram para a elaboração de políticas públicas, para o idoso de programas, cursos e projetos voltados para esta faixa etária e para desenhar na sociedade outra representação de velhice, mais justa e real, superando a pouco otimista que hoje se registra na realidade do país. Estes aspectos buscam oportunizar ações voltadas para a inserção social do idoso, possibilitando maior participação social em busca de uma vida mais saudável e com melhor qualidade.

A presente investigação foi resultado da Bolsa Produtividade em Pesquisa, financiada pelo CNPq.

Realizou-se uma revisão sistemática e síntese das pesquisas já realizadas sobre a terceira idade, sob o recorte educacional, na qual foram selecionadas como categorias de análise a Universidade Aberta para a Terceira Idade e a Educação para o idoso, em um recorte temporal de 2000 a 2011 em Programas de Pós-Graduação em Educação brasileiros, reconhecidos e recomendados pela CAPES. Para a identificação e seleção das dissertações e teses foram consultados o banco de teses da CAPES, bibliotecas digitais dos programas, cadernos de indicadores de avaliação dos programas-CAPES e o portal domínio público.

A pesquisa caracteriza-se como uma revisão bibliográfica; com o mapeamento das produções acadêmicas sobre a temática, buscou-se a análise e sistematização dos principais aspectos apresentados pelos pesquisadores sobre a temática, seguida de uma análise mais detalhada e rigorosa sobre o conhecimento produzido nos diferentes trabalhos, por meio de olhares e perspectivas distintas sobre o mesmo tema, fortalecer e possibilitar uma prática mais rica e efetiva.

Segundo Davies (2007), a revisão sistemática é uma pesquisa construída a partir dos dados registrados em diferentes pesquisas que abordam a mesma temática, com análise crítica de sua metodologia e conclusões com o intuito de possibilitar avanços no campo teórico e prático. 
A coleta das dissertações e teses analisadas aconteceu nos meses de outubro de 2009 a março de 2010, mas atualizados até a data atual, portanto só foram utilizadas para este estudo as dissertações e teses disponibilizadas no ambiente virtual.

Conforme levantamento realizado nos Cursos de Pós Graduação (Mestrado e Doutorado) em Educação reconhecidos e recomendados pela CAPES, foram registradas 25 teses e 110 dissertações nos anos de 2000 a 2011 no Brasil, em diferentes Instituições. De um total de 135 dissertações e teses registradas neste período, pode-se agrupá-las em 14 categorias distintas, entretanto, as categorias selecionadas para a análise foram a educação para o idoso com 19 trabalhos e a Universidade Aberta para a Terceira Idade, com 8 trabalhos, totalizado para este estudo 27 trabalhos.

O levantamento foi realizado em 42 programas de Pós Graduação em Educação, distribuídos nas diferentes regiões geográficas do país e o maior número de trabalhos acadêmicos sobre o tema concentra-se na Região Sul e Sudeste, além de ser nítido o interesse e o avanço nas pesquisas sobre esta temática nos quatro últimos anos.

Entre os anos de 2000 a 2005 foram encontrados 45 trabalhos (35\%) e nos anos de 2006 a 2009, praticamente dobrou, sendo 89 trabalhos (66,4\%). No ano de 2011 foi registrado 1 trabalho. Pode-se atribuir esse número de pesquisas ao próprio envelhecimento humano como um fenômeno acelerado, a busca por melhores condições de vida para esta faixa etária, ao respeito do idoso no que se refere à educação e a efetivação da prescrição legal quanto à criação de espaços educativos para o idoso, materializadas pelas universidades abertas para a terceira idade.

A análise seguiu um roteiro pré- estabelecido que registra a identificação, a metodologia, os principais estudiosos sobre a temática, o campo e os sujeitos de pesquisa, os instrumentos utilizados, a amostra da pesquisa e as principais contribuições de cada trabalho. Esta análise possibilitou identificar as contribuições, lacunas e fragilidades existentes nos trabalhos sobre as temáticas abordadas e que necessitam ser superadas com ações objetivas.

Com a síntese crítica dos trabalhos pode-se destacar os principais aspectos sobre as pesquisas sobre as temáticas Universidade Aberta para a Terceira Idade e educação para o idoso, com o intuito de aprofundar os estudos e incentivar/orientar novas pesquisas, ao mesmo tempo em que ao disseminar estes resultados por meio de artigos e pela participação em eventos científicos, possa influenciar na elaboração de políticas educacionais e possibilitar ações efetivas nesta área para satisfazer a demanda populacional.

A formulação e implementação de políticas educacionais para a terceira idade é uma necessidade diante do crescente contingente de idosos na sociedade brasileira, considerando a educação como um processo dialético e contraditório, com os condicionantes econômicos, políticos, culturais, sociais e ideológicos.

Universidade Aberta para a Terceira Idade e a Educação para o Idoso: categorias de análise das dissertações e teses

Embora a sociedade seja marcada por desigualdades, como preceito Constitucional no Brasil, firma-se que a educação é um direito de todos, sem qualquer distinção ou preconceito. E justamente, mediado pela educação que o homem adquire os conhecimentos e as manifestações culturais possibilitando o sentimento de pertencimento à sociedade na qual está inserido.

A educação possui um papel fundamental na formação crítica e na conscientização do idoso para que tenha condições de manter-se ativo e com autonomia na velhice. 
Possibilitar o acesso do idoso à educação é atitude necessária, democrática e compatível com os princípios da educação permanente.

Como afirmam Oliveira, Sortegagna e Oliveira (2011, p.90)

[...] tão fundamental quanto a cidadania, é o direito pela educação, pois não se alcançará a cidadania sem que haja conhecimento pleno deste direito. Logo, pensar a educação para a terceira idade, é pensar mais que uma ocupação para o idoso, é permitir uma ação intensiva e intencional para que este sujeito se perceba, endenta seu entorno social, político e econômico, como também não seja ludibriado ou tenha seus direitos negligenciados.

A educação ao longo da vida é, tanto em teoria quanto na prática, uma realidade que precisa ser respeitada e efetivada. No segmento menos privilegiado educacionalmente encontra-se o idoso que, embora se tenha avançado quantitativamente em iniciativas educacionais oferecidas a esta faixa etária, ainda apresenta um panorama distante do desejável e necessário. Neste contexto, o idoso é relegado a um quadro pouco animador porque são limitadas as iniciativas educacionais oferecidas a esta faixa etária sob a justificativa da incapacidade do idoso de aprender, de criar ou de inovar desta faixa etária.

A educação é um processo que caracteriza cada sociedade, fundamentada em uma concepção de homem, de mundo, ideais e objetivos, os quais variam no espaço e no tempo. O ser humano possui perspectivas, possibilidades, um ser inconcluso, e como tal necessita de uma educação ao longo da vida, na qual constantemente aprende, se desenvolve, compartilha experiências, saberes, estilos de vida, cultura que possibilitam a vida em sociedade. "A educação é o processo pelo qual a sociedade forma seus membros à sua imagem e em função de seus interesses" (PINTO, 1994, p.24).

A educação apresenta uma natureza contraditória, se de um lado reforça a conservação da sociedade, com suas características, hierarquia de poder, por outro lado, busca a superação e ruptura pela conscientização, crítica e emancipação humana.

A educação refere-se a existência humana em toda a sua plenitude, é um processo e um fato social. Vieira Pinto (2010) afirma ainda que pela educação o homem constitui a si próprio, é um processo de formação humana, do trabalho, de conscientização de si mesmo e do mundo. A educação é um fenômeno cultural, e ao mesmo tempo em que produz, também cabe à educação a transmissão da cultura de uma geração a outra.

Não somente os conhecimentos, experiências, usos, crenças, valores etc. a transmitir ao indivíduo, mas também os métodos utilizados pela totalidade social para exercer a ação educativa são parte do fundo cultural da comunidade e dependem do grau de seu desenvolvimento. Em outras palavras, a educação é a transmissão integrada da cultura em todos os seus aspectos, segundo os moldes e pelos meios que a própria cultura existente possibilita. O método pedagógico é função da cultura existente. O saber é o conjunto de dados da cultura que se têm tornado socialmente conscientes e que a sociedade é capaz de expressar pela linguagem (PINTO, 2010, p.33).

A educação sendo "um processo em que cada um aprende a se formar e a se informar a fim de transformar-se e transformar o mundo" (FURTER, 1975, p. 69), não se pode desconsiderar a sua dimensão política, na qual o desenvolvimento cultural aparece como forte instrumento para romper a dependência existente nas relações hierarquizadas socialmente, voltadas para relações mais igualitárias. 
A educação é uma prática política, de caráter permanente, permeando os homens em todos os espaços sociais, não podendo ser atribuída apenas à uma instituição, a escola, a responsabilidade de educar, mas é compromisso também da família e da sociedade.

A educação permanente se fortalece na aceitação da mudança para o desenvolvimento pessoal e social. Assim, "a educação permanente é a aprendizagem contínua de um estilo de vida adequado a uma sociedade que se considera, ela também, em permanente transformação e em constante desenvolvimento" (FURTER, 1975, p. 100).

A educação não pode ser baseada em uma concepção ingênua na qual o indivíduo é passivo e apenas receptor de conhecimentos, sendo desconsiderada qualquer experiência e conhecimento que possui, inferiorizando-o. Em contrapartida enfatiza-se a concepção crítica da educação que valoriza o conhecimento de cada indivíduo, seu contexto social, suas experiências e com base na prática social avalia a multiplicidade de aspectos que permeiam a vida humana, respeitando as particularidades.

A educação enquanto prática social media a transmissão da herança cultural acumulada pela sociedade, tem sua intencionalidade e finalidade, contemplando o homem em sua totalidade.

Assim, conforme afirma Oliveira (2012, p.34)

Entende-se dessa maneira que a realidade reclama novos espaços educativos baseados em novas políticas públicas que possibilitem ao idoso condições mais dignas de vida, exigindo não apenas mais reflexão sobre a constante mudança e envelhecimento da população, mas também aliar a uma ação mais ampla em relação à condição humana.

A educação possui um papel político fundamental, possibilita a troca de experiência e de saberes, com uma concepção democrática possui a essência de transformação, superando a mera transmissão de informações, instrumentalizando crítica e criativamente os indivíduos para a inovação da realidade (PICONEZ, 2002).

Assim, entende-se a relevância da educação como processo que oportuniza mudanças individuais e sociais, refletindo a necessária condição de libertação, de mudanças e de conquista da autonomia na terceira idade.

É indispensável o despertar de mais atenção e investimentos do Estado e
da sociedade civil para minimizar a precariedade de vida dos idosos. A
terceira idade, no Brasil, não constitui um fato econômico sério, e, assim,
não atrai maiores investimentos no setor. Essa situação, pela educação,
deve ser revertida (OLIVEIRA, R; SCORTEGANA, P.A.;
OLIVEIRA, F OLIVEIRA, D'ALENCAR, 2011, p.16).

Considerando que a educação é um processo que não se finda, acontece ao longo da vida, somada a prescrição legal de ser um direito do cidadão, o idoso precisa e tem o direito de ser educado e para que isto seja possível, devem ser oportunizados espaços educativos que correspondam às especificidades e demandas desta faixa etária.

Gadotti (1984, p. 69) afirma que, "a educação permanente visa uma educação rearranjada, refletida e integrada no seu todo. Ela sustenta a ideia de um controle de todos os recursos educativos possíveis de uma sociedade e de sua execução". Assim, a educação permanente não depende exclusivamente da educação formal, mas acontece por meio da educação não formal.

Como considera Paulo Freire (2011) é preciso aprender a leitura do mundo. O diálogo deve estar presente na educação do idoso para que ocorra a conscientização, 
apropriação de conceitos, direitos, entendimento do seu entorno, empoderamento em busca de uma melhor qualidade de vida. A prática educativa dialógica preserva a identidade e promove a cidadania.

"Nenhuma ação educativa pode prescindir de uma reflexão sobre o homem e de uma análise sobre suas condições culturais. Não há educação fora das sociedades humanas e não há homens isolados" (FREIRE, 2011, p.83).

Cabe assim, a educação estabelecer uma relação democrática entre a política e os sujeitos deste paradoxo educacional, a fim de re-ordenar e reconstruir gradativamente um processo ensino e aprendizagem pautado na construção e re-construção crítica, reflexiva e democrática dos conhecimentos, na qual todos os indivíduos presentes neste meio possam desenvolver-se e construírem-se como cidadãos atuantes e conscientes do seu papel social. O idoso readapta as suas condições sociais e os papéis sociais que assume no decorrer dos anos.

A educação permanente deve valorizar a aprendizagem e experiências adquiridas ao longo da vida pelos idosos, incentivando-os a serem produtores de cultura e novos conhecimentos, além de superar estereótipos e mitos sobre a incapacidade e improdutividade na terceira idade.

Portanto, conforme afirma Freire (apud GADOTTI, 1979, p.73)

\begin{abstract}
A educação de jovens e adultos deve ser sempre uma educação multicultural; uma educação que desenvolva o conhecimento e a integração na diversidade cultural, uma educação para a compreensão mútua contra a exclusão por motivos de raça, sexo, cultura e outras formas de discriminação, e para isso, o educador deve conhecer bem o seu próprio meio, o educando, pois somente conhecendo a realidade desses jovens e adultos é que haverá educação de qualidade.
\end{abstract}

A educação permanente irá possibilitar o desenvolvimento do idoso integral, sem preconceitos ou restrições, independente da classe social ou situação de marginalização em que esteja inserido, permitindo que ocorra o desenvolvimento intelectual, social, cultural e político. A educação para o idoso desenvolve a capacidade dele ver o mundo e compreender-se inserido nele de maneira significativa, como sujeito ativo e autônomo.

Segundo Delors (1999, p.18)

Parecer impor-se, cada vez mais, o conceito de educação ao longo da vida, dadas as vantagens que oferece em matéria de flexibilidade, diversidade e acessibilidade no tempo e no espaço. É a ideia de educação permanente que deve ser repensada e ampliada. Ela deve ser encarada como construção contínua da pessoa humana, dos seus saberes e aptidões, da sua capacidade de discernir e agir. Deve levar cada um a tomar consciência de si próprio e do meio ambiente que o rodeia, e a desempenhar o papel social que lhe cabe enquanto trabalhador e cidadão.

A educação embasada em uma concepção crítica e libertadora, transmissora de cultura oportuniza uma maior inserção social, fortalece a ideia de pertencimento e de conhecimento da cultura popular e erudita, o reconhecimento de si mesmo e do mundo no qual está inserido. Por meio da educação o homem adquire conhecimentos e se instrumentaliza em busca da emancipação política e em decorrência a emancipação humana. 
A educação tem função essencial junto ao idoso, é primordial para garantir a autonomia na velhice ao mesmo tempo em que constitui um direito fundamental de todo indivíduo, prescrito na legislação brasileira. Entretanto, ressalta-se a educação em diferentes modalidades: formal, não formal e informal. É na educação não formal que o idoso encontra uma diversidade de oportunidades e espaços para usufruir da cidadania em sua plenitude.

Muitas universidades brasileiras, públicas e privadas oferecem espaços educativos para os idosos por meio de Programas, Projetos ou Cursos, com diferentes terminologias entre as quais a Universidade Aberta para a Terceira Idade tem se fortalecido e atualmente é a mais aceita.

Desde a criação da primeira Universidade Aberta para a Terceira idade, em 1973, em Toulouse com Pierre Vellas "com o objetivo de tirar os idosos do isolamento, propiciar-lhes saúde, energia e interesse pela vida e modificar sua imagem perante a sociedade" (PALMA, 2000, p.53), estas iniciativas tem se disseminado pelo mundo.

Entretanto, apesar de ter crescido quantitativamente, as UATIs não são suficientes para satisfazer a demanda diante do grande número de idosos na população brasileira. Hoje, segundo pesquisa de Cachioni (2003) registram-se 100 cursos da universidade Aberta para, da ou à Terceira Idade. Em outra pesquisa, realizada por Teodoro (2006) são apontados 130 UATIs. No Paraná, na atualidade, são oferecidos 5 cursos para este público, sendo que cada um é desenvolvido em uma universidade estadual distinta.

Pode-se afirmar também que existem diferentes instituições e prefeituras que desenvolvem projetos para esta faixa etária, mas não de caráter permanente, e grande parte voltado mais para o lazer e o esporte, sem a preocupação ou o planejamento de aulas que ofereçam conhecimentos teóricos e que se voltam para o desenvolvimento e aprimoramento das capacidades intelectuais do idoso. Não se pode negar a relevância destes projetos, mas a preocupação reside que estas iniciativas valorizam o entretenimento e a diversão em detrimento da aprendizagem, da aquisição de conhecimentos e da atualização, o que de certa forma reforça o estereótipo negativo de incapacidade de aprendizagem atribuído ao idoso.

$\mathrm{Na}$ perspectiva da educação não formal, as UATI buscam "[...] oferecer possibilidades de experiências e vivências para que seu público faça novas escolhas e opções pessoais e sociais [...]" (SILVA, 2006, p.09), além de proporcionar a aquisição de conhecimentos, informações, ampliação de amizades, elevação de auto estima, valorização, maior inserção e participação social.

A partir do momento em que o estigma de incapacidade e improdutividade atribuído ao idoso é gradativamente superado, uma nova imagem é construída na qual o idoso e considerado um sujeito capaz de desenvolver e de desempenhar novos papéis sociais. Assim, a velhice vai sendo re-desenhada, o idoso passa a ser visto como um novo agente social.

Gradativamente, a visão de idosos como um subgrupo populacional vulnerável e dependente foi sendo substituída pela de um segmento populacional ativo e atuante que deve ser incorporado na busca do bemestar de toda a sociedade (CAMARANO; PASINATO, 2004, p.257-258).

A educação é fundamental na constituição desta nova imagem do idoso, na possibilidade de uma mudança cultural, da conscientização da sociedade sobre o processo de envelhecimento como natural e da velhice como uma fase da vida repleta de alegrias, sonhos, planos e conquistas. 
As UATIs fundamentam-se na concepção de educação permanente, educação não formal e autorrealização do idoso. Estruturam-se em uma abordagem multidisciplinar, priorizando o processo de valorização humana e social da terceira idade, refletindo constantemente sobre as questões referentes ao idoso nos diversos campos teóricos além de proporcionar uma melhor qualidade de vida ao idoso, tornando-o mais ativo, alegre, inserido e participativo socialmente.

Segundo Oliveira (2013, p.7),

A educação apresenta-se como propulsora da transformação social, pois é por meio dela que, além da aquisição de conhecimentos, o processo de socialização se intensifica, o empoderamento torna-se possível e a formação de um sujeito crítico e reflexivo se consolida.

As UATIs possibilitam uma maior visibilidade aos idosos, valorizando-os e estimulando a conscientização da sociedade em geral para esta faixa etária, despertando valores como respeito e justiça social.

\section{Categorias analisadas como temáticas de dissertações e teses}

Foram selecionadas para a análise duas categorias: universidade aberta para a terceira idade e educação para o idoso. Totalizaram 27 trabalhos, defendidos em Programas de Pós Graduação de 2000 a 2011, sendo que 19 (1 tese e 18 dissertações) versam sobre a educação para a terceira idade e 8 (dissertações) investigam as universidades abertas para a terceira idade.

Referentes a metodologia utilizada nas pesquisa, 3 são pesquisas bibliográficas e documental e 1 é estudo de caso. A pesquisa de campo também foi realizada em 15 das pesquisas. Utilizou-se a análise de conteúdo e a pesquisa predominante foi a qualitativa. Duas pesquisas explicitaram a natureza quanti-qualitativa.

Para a coleta de dados, os instrumentos utilizados foram: observações sistemáticas, questionário, entrevista e diário de campo.

As políticas educacionais foram abordadas em 14 trabalhos e explicitadas como justificativa para a temática investigada, embora denunciem a desconsideração do idoso nas políticas educacionais, as quais até pouco tempo eram vistas como assistencialistas e compensatórias. Neste contexto, reflete-se sobre a necessidade que sejam incrementadas políticas educacionais mais específicas, respeitando as particularidades que esta faixa etária exige.

Duas pesquisas explicitam a relevância de investimento na formação do professor para a área de educação tanto na modalidade da EJA quanto para os professores das UATIs. Sabe-se que os idosos possuem características diferenciadas e exigem uma metodologia própria no processo de aprendizagem, assim como materiais específicos.

No quesito dos objetivos das pesquisas, nota-se uma diversidade, entretanto buscam analisar as atividades e as ações educativas oferecidas aos idoso, em especial enaltecendo o respeito à diversidade, habilidades e limites característicos da idade; verificar o significado do aprender e do ensinar para os idosos; investigar a necessidade da escola para os idosos como condição para usufruírem da educação como um direito de todo cidadão; identificar os motivos e as expectativas que levam os idosos a voltar a estudar, seja na EJA ou na UATI.

Uma das dissertações salientou o desconhecimento da sociedade em geral sobre o Estatuto do Idoso. Embora a referida Lei preconize a criação de universidades abertas para 
a terceira idade, o que tem se disseminado consideravelmente nos últimos anos com a estrutura de Programas, Cursos e Projetos, ainda não são suficientes para atender a procura dos idosos pela educação. A falta de financiamentos e apoio das Agências de Fomento para pesquisas nesta área também possam ser responsáveis por esta tímida ampliação de ofertas educacionais para o idoso nas instituições de ensino superior.

Segundo 10 trabalhos, a educação possui impacto positivo porque possibilita a informação e aquisição de novos conhecimentos, a ampliação de amizades, melhoria na qualidade de vida e da saúde, possibilita maior inserção e participação social, oportuniza o desenvolvimento de mais habilidades, reivindicação de direitos e pleno exercício da cidadania.

Com relação a categoria universidade aberta para a terceira idade, todas as dissertações foram estudos de caso de uma UATI, sendo da UERJ ( 3 trabalhos) e os outros 5 investigaram a UATI da PUCCAMP.

Dos 8 trabalhos, 3 fizeram menção às políticas públicas, sob o recorte educacional, mas não fizeram muitas considerações a respeito, restringindo-se como justificativa para a investigação realizada. Um aspecto que chamou a atenção refere-se a falta de contextualização da UATI na própria instituição, não retratando o processo para a criação ou mesmo o contexto sócio econômico e a sua evolução até os dias atuais.

As temáticas pesquisadas dentro desta categoria apresentaram-se variadas: educação permanente, análise e avaliação da universidade aberta para a terceira idade, temática ambiental, adesão e evasão dos alunos da UATI, a relação professor-aluno na UATI, autobiografia dos alunos da UATI e características e perfil dos docentes da UATI.

Embora a literatura sobre as referidas categorias tenha crescido sensivelmente na última década, percebe-se que as pesquisas oferecem um referencial de estudiosos brasileiros, o que anteriormente baseava-se em estudiosos estrangeiros, entre os quais hoje pode-se considerar: Veras(1995), Palma(2000), Jordão Netto (1997), Beauvoir (1990), Néri (1991, 1995), Both (2001), Cachioni (2003), Oliveira (1999, 2010, 2011).

Registra-se nas pesquisas uma ausência de teorias sobre o envelhecimento e a velhice, mas em contrapartida reforça-se a relevância e o direito do idoso à educação enquanto instrumento de empoderamento e emancipação.

Um ponto comum em 6 trabalhos é o surgimento da primeira UATI na França e a disseminação destas iniciativas educacionais pelo mundo, porém com terminologia variada. Outro aspecto abordado por todos os trablahos é a educação permanente como concepção que fundamenta a educação para o idoso.

Constata-se também a utilização da entrevista e de questionário com idosos como predominante, enfatizando a educação permanente e reflexões sobre a UATI, motivos que levaram os idosos a voltar a estudar, mudanças de comportamentos após frequentarem a UATI.

Diferentes iniciativas educacionais para os idosos, sob a terminologia da UATI, apresentam resultados significativos e grande influência positiva na vida dos idosos, instrumentalizando-os com conhecimentos, proporcionando uma nova visão de mundo, mais otimista, estimulando-os a uma vida mais saudável, com maior participação social e, como decorrência oportunizando o empoderamento e uma gradativa emancipação do idoso. Como desafio maior, a longo prazo possibilitam a superação de fragilidades e situações de vulnerabilidade as quais o idoso está exposto e a superação de estigmas negativos, de marginalização, desrespeito e desvalorização desta faixa etária por meio de uma mudança cultural, pela conscientização do processo de envelhecimento pela sociedade em geral. 
Um dos aspectos relevantes destas pesquisas acadêmicas é possibilitar maior visibilidade do idoso na sociedade brasileira, despertando uma visão diferente, desmistificando estereótipos culturalmente elaborados, oportunizando maior participação e inserção social, respeitando o direito do idoso à educação e valorizando os diferentes espaços educacionais para esta faixa, entre os quais, a UATI.

Ao mesmo tempo, estimulam outros pesquisadores a se interessarem em pesquisar esta temática, e conscientizar a população da necessidade da elaboração e implementação de políticas públicas para o idoso na tentativa de contribuir para uma vida de melhor qualidade, mais saudável e respeitosa para o grande número de idosos na sociedade brasileira.

A superação da educação para o idoso como compensação ou assistencialismo é premente, em contraposição é necessária a valorização das capacidades intelectuais, a sabedoria, as experiências e habilidades adquiridas ao longo da vida.

\section{Considerações Finais}

A temática da educação para o idoso e a Universidade Aberta para a Terceira Idade foram as categorias selecionadas para a realização de um levantamento das dissertações e teses que possuem esta temática como objeto de estudo. A análise destes trabalhos resultou neste artigo. E, com maior amplitude também foram abordadas as políticas públicas e educacionais voltadas para esta faixa etária. Esta análise referenciou as principais contribuições e fragilidades das abordagens realizadas nos trabalhos acadêmicos selecionados.

As pesquisas sobre a temática buscam deslocar o eixo do envelhecimento enquanto fenômeno individual e inevitável para uma questão social considerando um dos grandes desafios para a sociedade brasileira o seu envelhecimento populacional enquanto uma realidade social e política, superando a do envelhecimento biológico em detrimento da lógica do capital em uma sociedade capitalista, na qual prescreve o destino dos indivíduos conforme sua relação com as condições materiais de produção e reprodução social, imprimindo um perfil diferenciado a cada um conforme a classe, hierarquias e status sociais.

Entre os mitos e preconceitos excludentes com relação ao idoso está a incapacidade de aprender, sem comprovação científica, mas como justificativa para a falta de investimento na educação para o idoso; aos poucos vai perdendo sua credibilidade à medida que muitos idosos ainda estão no mercado de trabalho, produtivos e de grande destaque, desmentindo tal preceito.

O interesse pelas pesquisas sobre as temáticas selecionadas para este estudo cresceu significativamente nos últimos anos, entretanto ainda são incipientes e em número reduzido se comparadas com outros tema, o que pode ser atribuído a falta de conscientização do envelhecimento acelerado da população brasileira, considerado um tema relativamente novo; o pequeno apoio de órgãos financiadores de pesquisas com esta temática, a falta de valorização e espaço para discussão do tema em eventos de educação em nível nacional e como consequência a falta de visibilidade do pesquisador dessa temática.

Os trabalhos analisados apresentam-se muito descritivos e pouco analíticos, não apresentam uma metodologia muito clara, trabalhando mais com os dados coletados em entrevistas e questionários e pouco pressupostos teóricos.

Outro aspecto relevante é a falta da apresentação do contexto sócio-político e econômico tanto da criação como da atualidade no qual a UATI está inserida e também a 
posição que ocupa dentro da instituição a que pertence. Pode-se considerar que as UATIs não são investigadas de maneira crítica, mas as abordagens são superficiais e descritivas.

Todos os trabalhos analisados explicitam a necessidade de políticas educacionais para a terceira idade, orientações legais para a criação e implementação de UATI no Brasil que vão ao encontro das particularidades da faixa etária.

Embora com essas críticas ressalta-se que as pesquisas favoreceram a uma maior visibilidade do idoso no contexto social brasileiro, estimulando a mídia na divulgação de uma imagem positiva desta faixa etária, além de mais estudiosos para a realização de outras investigações que tem como objeto central o idoso, em toda a complexidade que o fenômeno do envelhecimento e da velhice encerram e a diversidade de fatores que englobam.

Com o rigor científico e a seriedade que as dissertações e teses possuem, pela abordagem dessa temática, um dos maiores compromissos dos estudiosos da área é conscientizar a sociedade política e civil sobre a questão do envelhecimento pessoal e social como uma realidade emergente e a busca de uma nova representação do idoso e da velhice, em detrimento de estigmas negativos e infundados cientificamente, mas culturalmente fortalecidos e cristalizados.

$\mathrm{O}$ empoderamento do idoso, inserido em uma cultura a qual pertence e mediado pela educação e atividades socioculturais possibilita a elaboração de novos símbolos e representações sociais da velhice e do idoso, além de uma construção cultural mais otimista, mais real superando o simbólico estabelecido na esfera cultural de impotência, limitações e desvalorização social.

Hoje emerge gradativamente outro paradigma da velhice, no qual o idoso é um ser pensante, participativo, com direitos e deveres, com experiência e sabedoria, mais ativo, saudável, valorizado e respeitado, capaz de crescer intelectualmente, planejar, sonhar e realizar seus sonhos.

A representação do idoso no contexto atual não é nada otimista, atribuindo a esta faixa etária mais limitações, estereótipos negativos e incapacidades do que perspectivas e projeções otimistas de futuro.

É tarefa premente de todos os estudiosos e educadores, que tenham como temática, o envelhecimento e o idoso, romper com preconceitos, estigmas e mitos sobre a velhice e o idoso, influenciando a sociedade e intervindo no esboço de uma nova representação social da velhice, delineia-se a mudança, a busca por novos valores e conhecimentos que constituem os maiores desafios nesta empreitada de um projeto educativo para o idoso, e emergencialmente é essencial a busca de alternativas educacionais que garantam mais ações práticas para uma integração e maior participação do idoso na sociedade.

A educação para o idoso apresenta-se como um direito fundamental a todo ser humano, o qual está presente na legislação brasileira, mas ainda não existe nenhuma política que referencie exclusivamente a educação para esta faixa etária.

A educação para o idoso, por meio das UATIs, deve basear-se em uma nova representação de idoso, que atua não para legitimar, intensificar as discriminações ou desvalorizar esta faixa etária enfatizada pela sociedade; mas paradoxalmente deve voltar-se para desenvolver o senso crítico do idoso, estimular a criatividade e a participação, contribuindo para que o idoso seja protagonista da própria história e assim despertar maior credibilidade e reconhecimento da sociedade, no potencial do idoso ser um eterno aprendiz 


\section{Referências}

BONETI, L. W. Educação, exclusão e cidadania. Ijuí: Unijuí, 1997.

BOTH. A. Educação Gerontológica: posições e proposições. ERechim: São Cristovão, 2001.

BRASIL. Lei n. 8.842 de 4 de janeiro de 1994. Dispõe sobre a Política Nacional do Idoso. Brasília, 1994.

BRASIL. Lei n. 10741 de 03 de outubro de 2003. Dispõe sobre o Estatuto do Idoso. Brasília, 2003.

CACHIONI, Meire. Quem educa os idosos? Um estudo sobre professores de universidade da terceira idade. São Paulo: Alínea, 2003.

CAMARANO, A. A; PASINATO, M. T. O envelhecimento populacional na agenda das políticas públicas. In: CAMARANO, A. A. (Ed.). Os novos idosos brasileiros: muito além dos 60? Rio de Janeiro: IPEA, 2004, p. 253-292.

DAVIES, P. Revisões sistemáticas e Campbell Collaboration. In: THOMAS, G.; PRING, R. Educação baseada em evidências: a utilização dos achados científicos para qualificação da prática pedagógica. Porto Alegre: Artmed, 2007. p. 31-43.

DELORS, J. Educação: um tesouro a descobrir. São Paulo: Cortez. Brasília: MEC, UNESCO, 1999.

FREIRE, P. Educação e mudança. $2^{\mathrm{a}}$ ed. São Paulo: Paz e Terra, 2011.

FURTER, P. Educação e vida. Petrópolis: Vozes,1975.

GADOTTI, M. A educação contra a educação. Rio de Janeiro: Paz e Terra, 1984.

História das ideias pedagógicas. São Paulo: Ática, 1979.

IBGE. Censo demográfico 2010. Rio de Janeiro: Fundação Instituto Brasileiro de Geografia e Estatística, 2010.

JORDÃO NETTO, A. Gerontologia Básica. São Paulo: Lemos, 1997.

NERI. A.L. Envelhecer num país de jovens. Campinas: Unicamp, 1991. Psicologia do Envelhecimento. Campinas: Papirus, 1995.

OLIVEIRA, R. C. S. Terceira idade: do repensar dos limites aos sonhos possíveis. Campinas: Papirus, 1999.

OLIVEIRA, R. C. S.; SCORTEGAGNA, P. A.; OLIVEIRA, F. S. O envelhecimento e a velhice: teorias, demografia e política. Curitiba: CRV, 2011.

OLIVEIRA, R.C.S. A pesquisa sobre o idoso no Brasil: diferentes abordagens sobre educação nas teses e dissertações (de 2000 a 2009). Acta Scientiarum Education, Maringá, v.35, n.1, p. 1-11, jan-june.

PALMA, L. T. S. Educação permanente e qualidade de vida: indicativos para uma velhice bem-sucedida. Passo Fundo: UPF, 2000.

PICONEZ, S. Educação escolar de jovens e adultos. São Paulo: Setembro, 2009.

PINTO, A. V. Sete lições sobre a educação de adultos. São Paulo: Cortez, 1994. 
PINTO, A. V. Sete lições sobre educação de adultos. 16ª ed. São Paulo: Cortez, 2010.

SILVA, R. Fundamentos teóricos e metodológicos da pedagogia social no Brasil. In: CONGRESSO INTERNACIONAL DE PEDAGOGIA SOCIAL, 1, 2006, São Paulo. Anais ... São Paulo: Universidade de São Paulo, 2006. p. 01-18.

TEODORO, M. F. M. UnATI/UERJ: uma proposta de educação permanente para o cidadão idoso. 2006. 175p. Dissertação (Mestrado em Educação), Faculdade de Educação, Universidade Católica de Petrópolis, Rio de Janeiro, 2006.

VERAS, R. Terceira Idade: um envelhecimento digno para o cidadão do futuro. Rio de Janeiro: Relume/Dumará, 1995.

Notas

\footnotetext{
${ }^{1}$ Pedagoga. Doutora em Educação. Professora Permanente do Mestrado e Doutorado em Educação da Universidade Estadual de Ponta Grossa. Coordenadora do Programa da Universidade Aberta para a Terceira Idade na UEPG. Pesquisadora Produtividade do CNPq. E-mail: soliveira13@uol.com.br
}

Recebido em julho-2013

Aprovado em setembro-2013 